\title{
Crystal engineering in confined spaces. A novel method to grow crystalline metal phosphonates in alginate gel systems $\dagger$
}

\author{
Nikoleta Stavgianoudaki, ${ }^{a}$ Konstantinos E. Papathanasiou, ${ }^{a}$ Rosario M. P. Colodrero, ${ }^{b}$ Duane Choquesillo- \\ Lazarte ${ }^{c}{ }^{\text {Juan M. Garcia-Ruiz }},{ }^{c}$ Aurelio Cabeza, ${ }^{b}$ Miguel A. G. Aranda ${ }^{b}$ and Konstantinos D. Demadis ${ }^{* a}$
}

Received 24th April 2012, Accepted 1st June 2012

DOI: $10.1039 / \mathrm{c} 2 \mathrm{ce} 25632 \mathrm{k}$

In this paper we report a crystal growth method for metal phosphonate frameworks in alginate gels. It consists of a metalcontaining alginate gel, in which a solution of phosphonate ligand is slowly diffused. Crystals of metal phosphonate products are formed inside the gel. We have applied this for a variety of metal ions (alkaline-earth metals, transition metals and lanthanides) and a number of polyphosphonic acid and mixed carboxy/phosphonic acid ligands.

Metal phosphonate chemistry has been steadily growing as a modern field of inorganic/materials chemistry. Very recently the first concise book was published in the field. ${ }^{1}$ Central to the area of coordination polymers is the access to acceptable quality crystalline materials for full structural characterization. ${ }^{2}$ Ideally, appropriate-sized single crystals are sought for single crystal X-ray determination, however there are several cases where final structures were obtained based on powder data. ${ }^{3}$ In addition,

${ }^{a}$ Crystal Engineering, Growth and Design Laboratory, Department of Chemistry, University of Crete, Voutes Campus, Crete, GR-71003, Greece.E-mail: demadis@chemistry.uoc.gr

${ }^{b}$ Departamento de Química Inorgánica, Universidad de Málaga, Campus Teatinos s/n, 29071-Málaga, Spain

${ }^{c}$ Laboratorio de Estudios Cristalográficos, IACT-CSIC, Granada, Spain $\uparrow$ Electronic Supplementary Information (ESI) available: powder XRD patterns for bulk samples of all materials reported, detailed experimental strategy, crystallographic cif files for Ca-PMIDA (CCDC 870777), CaHEDP (CCDC 870776), Ca-AMP (CCDC 870775), and Mg-PMIDA (CCDC 877820). See DOI: 10.1039/c2ce25632k new techniques and synthesis approaches are put forth in order to obtain new materials. In metal phosphonate chemistry ambient conditions ("mild" conditions) 4 and hydrothermal/solvothermal syntheses ("harsh" conditions) ${ }^{5}$ are common in the literature, and recently, high-throughput approaches have been successfully tested. ${ }^{6}$

In this Communication we present a novel method to grow single crystals of metal phosphonate compounds in alginate gels and under ambient conditions. The advantages of this method are: (a) use of small amounts of reagents, (b) control of certain parameters, such as $\mathrm{pH}$ and reactant molar ratios, (c) easy and practical to use in any synthetic laboratory, (d) the nature of the method is based on the creation of a "local" microenvironment around the metal ion, which is not free, but coordinated by the carboxylate moieties of the alginate gel, (e) the above conditions may lead to new structure types, not accessible by conventional syntheses.

Alginate-based gels have been thoroughly studied. ${ }^{7}$ Our interest was drawn to those gels that contain metal ions, mostly divalent (e.g. alkaline-earth and first-row transition metals) and trivalent (e.g. lanthanide) ones. Metal-containing alginate gels are easily prepared.t In our experiments gelation took place within minutes, when a divalent or trivalent metal ion salt is added to the sodium alginate solution. $\mathrm{Na}^{+}$ions are easily exchanged with added $\mathrm{M}^{n+}$ $(n>1)$ ions. Hence, a metal alginate hydrogel is formed due to metal-carboxylate bond formation. Since hydrogels are loosely held systems, water (and reagents dissolved in it) can easily penetrate and be inserted into their interior. Hence, we
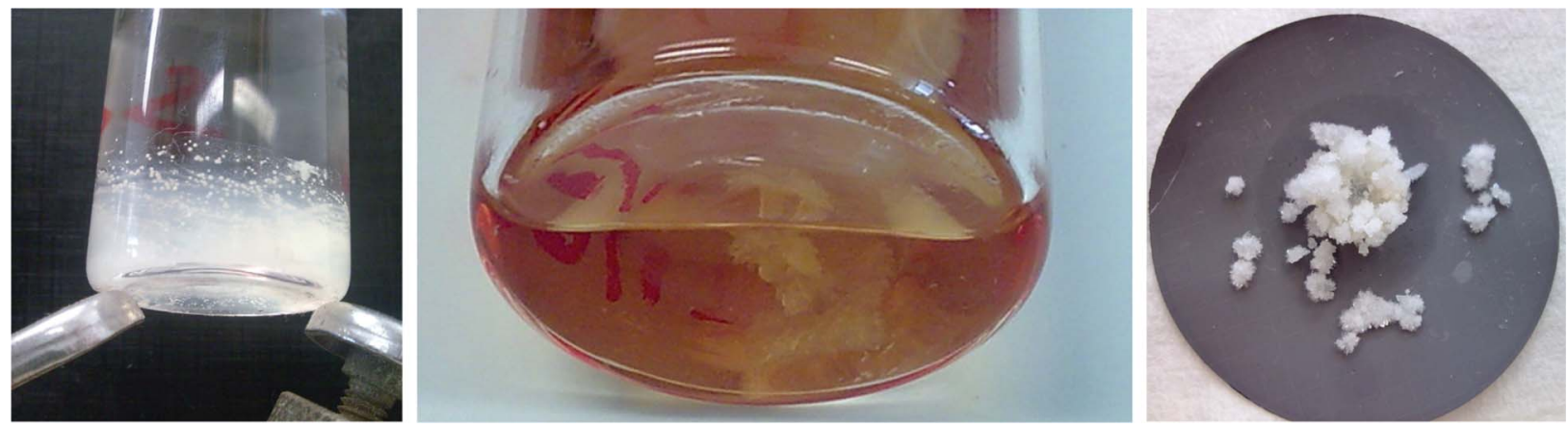

Fig. 1 Initial stages of crystal formation in the alginate gel (left). Crystal growth (middle). Isolated single crystals (right). 
Table 1 Morphological characteristics of some metal phosphonate crystalline materials grown in alginate gels

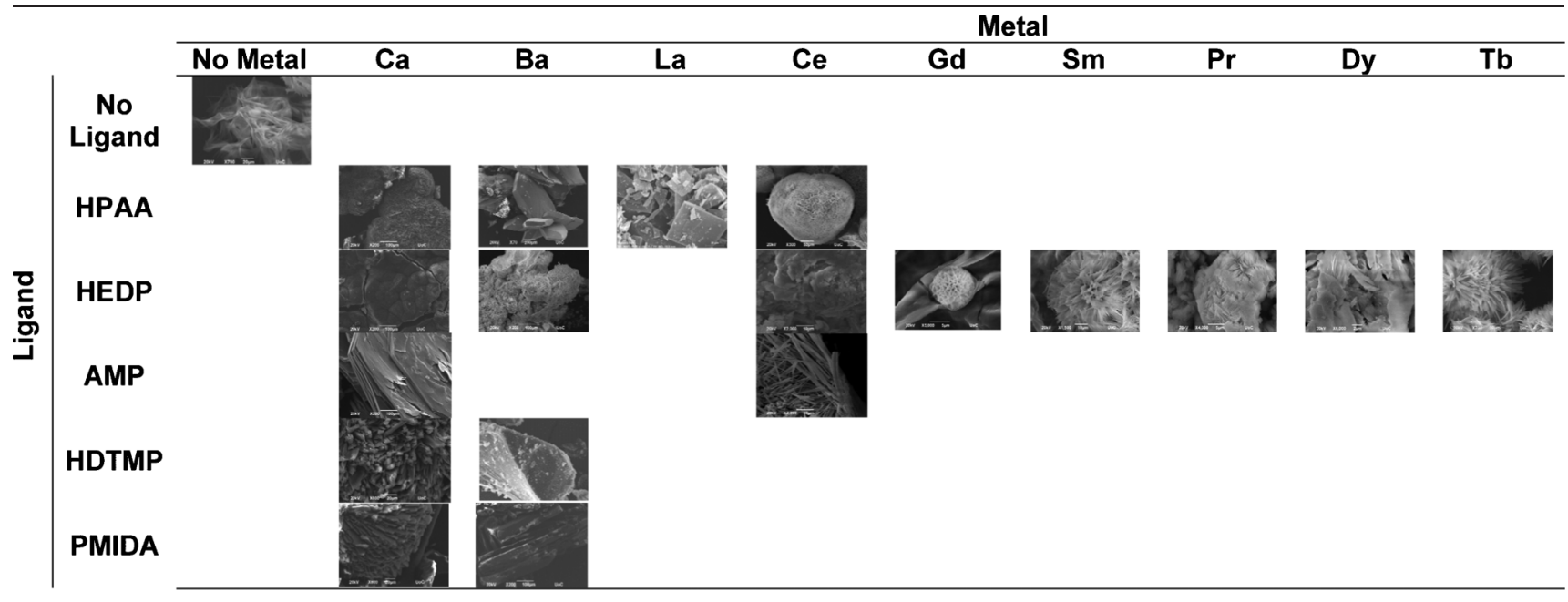

hypothesized that if the water solution around the gel contains a desirable ligand (phosphonate), slow diffusion of the ligand into the inner body of the gel may allow crystal formation and further, slow growth of the metal phosphonate product. Based on the hundreds of experiments performed so far (see ESI $\dagger$ ), the methodology yields crystalline materials. In Fig. 1 three stages of the strategy are shown. Furthermore, in Table 1 we show morphological features of a representative list of compounds formed by gel crystallization.

It is obvious that using this method of crystallization a large number of crystalline metal phosphonate materials can be obtained. Hence, for the purposes of this Communication we present herein a representative sample of crystal structures of three calcium and one magnesium phosphonate solid crystallized by this particular gel method.

The structure of Ca-PMIDA, $\mathrm{Ca}\left[\left(\mathrm{OOCCH}_{2}\right)_{2} \mathrm{~N}(\mathrm{H})-\left(\mathrm{CH}_{2} \mathrm{PO}_{3} \mathrm{H}\right)\right.$ $\left(\mathrm{H}_{2} \mathrm{O}\right)$ ], is a 2D layered material. The $\mathrm{Ca}^{2+}$ center is found in an octahedral environment shaped by two monodentate phosphonate oxygens (in trans positions), three monodentate carboxylate oxygens (in a mer configuration) and one Ca-bound water molecule (Fig. 2).

The phosphonate and one carboxylate moieties act as bridging groups between $\mathrm{Ca}^{2+}$ ions. The second carboxylate group coordinates in a terminal fashion. $\mathrm{Ca}-\mathrm{O}$ bond distances fall in the range of 2.259 to $2.412 \AA$. The $\mathrm{Ca}-\mathrm{O}\left(\mathrm{H}_{2} \mathrm{O}\right)$ is $2.314 \AA$. The three-dimensional crystal structure can be more precisely described as "pillared", with the PMIDA dianions (organic layer) acting as organic pillars between the $\mathrm{Ca} / \mathrm{O}$ inorganic layer. There are no lattice waters of crystallization.

Ca-HEDP, $\mathrm{Ca}\left[\left(\mathrm{HO}_{3} \mathrm{P}\right)_{2} \mathrm{C}\left(\mathrm{CH}_{3}\right)(\mathrm{OH})\right]\left(\mathrm{H}_{2} \mathrm{O}\right)_{2}$, is also a $2 \mathrm{D}$ layered material. The layers are composed of a $\mathrm{Ca}$-phosphonate network. There is substantial hydrogen bonding between the layers. Each $\mathrm{Ca}^{2+}$ center is found in a distorted bicapped octahedral environment shaped by four phosphonate oxygens, one terminally bound water molecule, the $-\mathrm{OH}$ group of the HEDP and two bridging water molecules (Fig. 3). There are no lattice waters of crystallization.
The product Ca-AMP, $\mathrm{Ca}\left[(\mathrm{H}) \mathrm{N}\left(\mathrm{CH}_{2} \mathrm{PO}_{3} \mathrm{H}\right)_{3}\left(\mathrm{H}_{2} \mathrm{O}\right)\right] \cdot 3.5 \mathrm{H}_{2} \mathrm{O}$, is also a 2D layered material, see Fig. 4. In contrast to the CaPMIDA structure, this one is not pillared. The layers are held together via hydrogen bonds with the interlayer lattice water

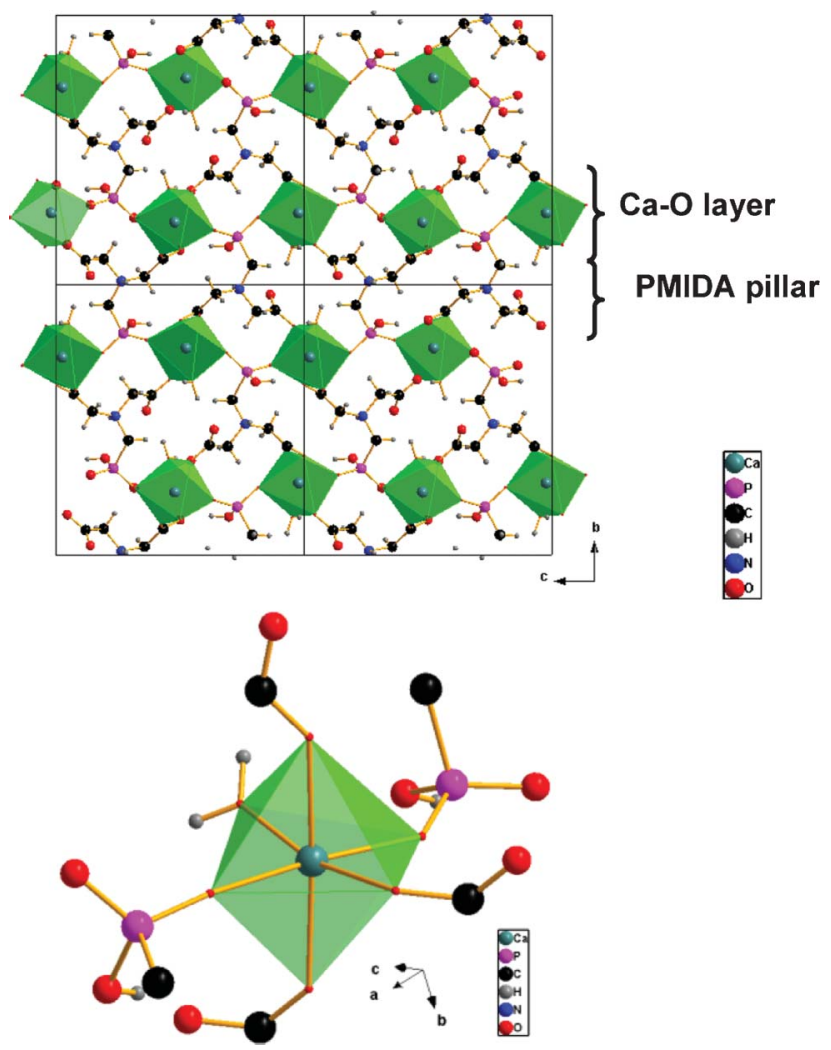

Fig. 2 Upper: the 2D pillared structure of Ca-PMIDA along the $c$ axis. Lower: the distorted octahedral coordination environment of the $\mathrm{Ca}$ centre, showing only the coordinating fragments from the PMIDA ligand, for clarity. 

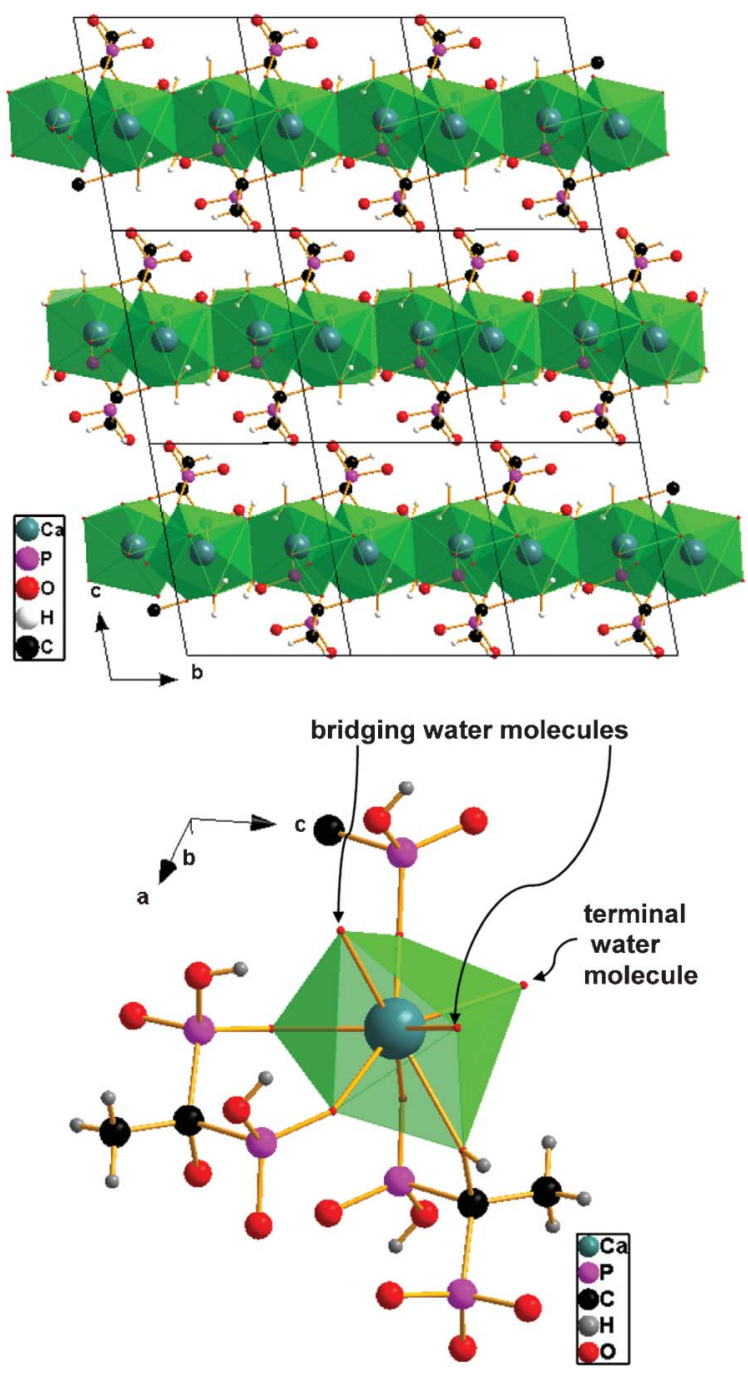

Fig. 3 Upper: the 2D layered structure of Ca-HEDP along the $a$ axis. Lower: the 8-fold coordination environment of the $\mathrm{Ca}$ centre, showing the coordinating fragments from three different HEDP ligands, and the terminal (one) and bridging (two) water molecules.

molecules. One of the lattice waters (O14) displays positional disorder (see Fig. 4). The structure obtained in this work is the same as previously reported, albeit by different methodology. ${ }^{8}$

The structure of Mg-PMIDA presents a number of peculiarities, see Fig. 5. First, it is not a coordination polymer, but a complex. The $\mathrm{Mg}^{2+}$ centre is found in an octahedral environment, with four water molecules being the equatorial ligands, whereas two monoanionic PMIIDA anions occupying the two axial positions. Each PMIDA ligand has one phosphonic acid and one carboxylic acid monodeprotonated. Furthermore, one PMIDA ligand is $\eta^{1}$ coordinated via its phosphonate group, whereas the other is $\eta^{1}$ coordinated via its carboxylate group. The $\mathrm{N}$ atom is protonated, as expected.

In conclusion, herein we presented a practical and easy-to-apply crystal growth technique. Thus far, we have been focused on growth of crystals of metal phosphonate materials. However, this methodology could be potentially applied to the growth of single crystals of any complex compound from water-soluble reactants. The present strategy is an addition to other, well-established

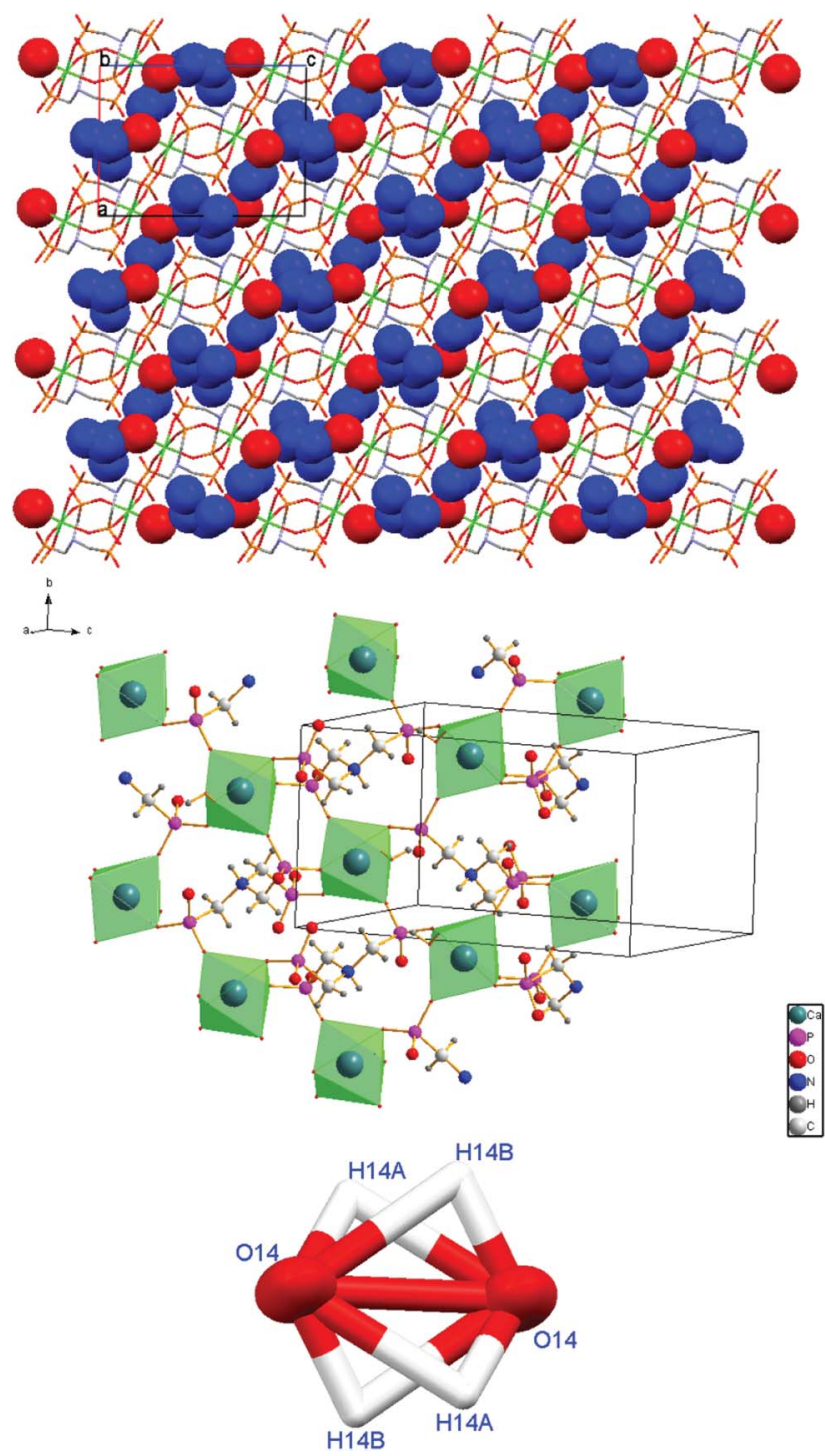

Fig. 4 Upper: the 2D layered structure of Ca-AMP with exaggerated interlayer lattice waters (blue spheres) along the $b$ axis. The Cacoordinated water molecules are shown as large red spheres. Middle: view of a single layer. Lower: the positional disorder of one of lattice waters (O14).

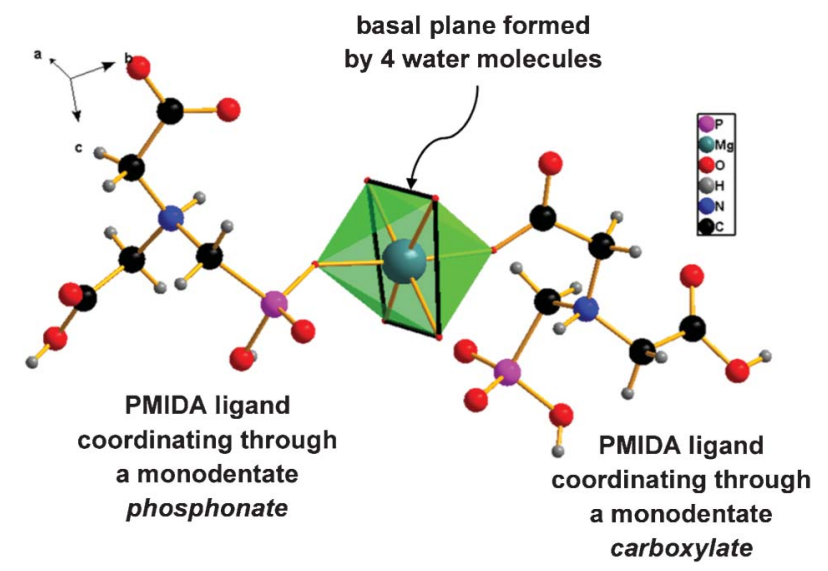

Fig. 5 The structure of Mg-PMIDA showing the different monodentate coordination modes of the two PMIDA ligands. 
techniques, such as layer diffusion, vapour diffusion, silica-based gel methods ${ }^{9}$ (with tetraethyl or tetramethylorthosilicate precursors), and in gelled organic solvents (with poly(ethylene) oxides). ${ }^{10}$

\section{Acknowledgements}

The work at UoC was supported by a grant from the Research Committee of the University of Crete, ELKE, (KA 3517). The work at UMA was funded by MAT2010-15175 research grant (Spain) which is co-funded by FEDER. The project "Factoría de Cristalización, CONSOLIDER INGENIO-2010" provided $\mathrm{X}$-ray structural facilities for this work.

\section{References}

\$ All metal salts, phosphonic acids and sodium alginate were obtained from commercial sources. Stock solutions of sodium alginate $(1 \% \mathrm{w} / \mathrm{v})$, metal salts $(100 \mathrm{mM})$ and phosphonic acids $(13.33 \mathrm{mM})$ were prepared in deionized water. The phosphonic acids tested as ligands were: aminotris(methylenephosphonic acid) (AMP), hydroxyethyledine-diphosphonic acid (HEDP), N-phosphonomethyimino-diacetic acid (PMIDA), ethylenediamine-tetrakis(methylenephosphonic acid) (EDTMP), hexamethylenediamine-tetrakis(methylenephosphonic acid) (HDTMP), diethylenetriamine-pentakis(methylenephosphonic acid) (DTPMP), hydroxyphosphonoacetic acid (HPAA), bis-hexamethylenetriaminepentakis(methylenephosphonic acid) (BHTPMP), 2-phosphonobutane-1,2,4-tricarboxylic acid (PBTC). A volume $(2 \mathrm{~mL})$ of each metal salt solution was transferred into a $25 \mathrm{~mL}$ glass vial and thoroughly mixed with $4 \mathrm{~mL}$ of the sodium alginate stock solution. The mixture was left undisturbed (to avoid the creation of air bubbles) for at least $9 \mathrm{~h}$, to ensure a complete exchange of $\mathrm{M}^{n+}$ for $\mathrm{Na}^{+}$ions. A sponge-like white hydrogel formed. After the removal of excess liquid the hydrogel was rinsed several times using deionized water and was sealed in a $25 \mathrm{~mL}$ vial. At this point the gel was ready to be reacted with the ligand solution. A volume $(15 \mathrm{~mL})$ of each ligand stock solution was pretreated either with $\mathrm{NaOH}$ or $\mathrm{HCl}$ solutions in order to obtain the desired $\mathrm{pH}$ value (e.g. for alkaline-earth metals a $\mathrm{pH}$ range 1.0-5.0 (with intermediate values differing by 0.5 units); for lanthanides the $\mathrm{pH}$ range was $0.2-1.0$ (with intermediate values differing by 0.2 units)). $\mathrm{pH}$ values above 6 must be avoided, because the gel does not form. The abovedescribed ligand solutions were added to the vials containing the gels. Each vial was sealed with parafilm and left undisturbed until single crystals are spotted by the naked eye. Crystal formation is dependent on the particular characteristics of each system and can last 2-30 days. Crystals were formed both on the surface and within the main body of the hydrogels. They were mechanically separated from the gel, rinsed with deionized water and stored in air-tight containers for further characterization. The crystalline metal phosphonates presented herein were isolated from the following experiments (at indicated $\mathrm{pH}$ values), as noted in the ESI†: Ca-PMIDA sample \# 177 (pH 2.85), Ca-HEDP sample \# 72 (pH 3.02), Ca-AMP sample \#'s 63-66 (pH 2.04-2.99), and Mg-PMIDA sample \# 178 ( $\mathrm{pH} 4.50$ ). Elemental analyses for the four compounds are reported. Calcd for $\mathrm{C}_{5} \mathrm{H}_{10} \mathrm{CaNO}_{8} \mathrm{P}$ (Ca-PMIDA): $\mathrm{C}$ $21.19 \%$, H $3.53 \%$, N 4.94\%. Found: C $21.56 \%$, H $3.66 \%$, N 5.01\%. Calcd for $\mathrm{C}_{2} \mathrm{H}_{10} \mathrm{CaO}_{9} \mathrm{P}_{2}$ (Ca-HEDP): C $8.57 \%$, H $3.57 \%$, N $0.00 \%$. Found: $\mathrm{C}$ $8.43 \%, \mathrm{H} 3.65 \%, \mathrm{~N} 0.00 \%$. Calcd for $\mathrm{C}_{3} \mathrm{H}_{19} \mathrm{CaNO}_{13.5} \mathrm{P}_{3}$ (Ca-AMP): C $10.13 \%$, H $3.39 \%$, N 3.94\%. Found: C $10.09 \%$, H $3.40 \%$, N 3.79\%. Calcd for $\mathrm{C}_{10} \mathrm{H}_{30} \mathrm{MgN}_{2} \mathrm{O}_{20} \mathrm{P}_{2}$ (Mg-PMIDA): C 20.53\%, H 5.13\%, N $4.79 \%$. Found C, 20.39; H, 5.38; N, 4.66. Crystallographic information: CaPMIDA. Data were collected on a Nonius Kappa CCD area detector diffractometer at 293(2) K with Mo-K $\alpha(\lambda=0.71073 \AA)$. Rectangular colorless plates $(0.10 \times 0.07 \times 0.09 \mathrm{~mm})$, chemical formula $\mathrm{C}_{5} \mathrm{H}_{10} \mathrm{CaNO}_{8} \mathrm{P}, \mathrm{FW}=283.19$, monoclinic, space group $P 2_{1} / n$, with $a$ $=5.3340(2) \AA, b=14.2250(3) \AA, c=13.0920(4) \AA, \beta=92.1210(14)^{\circ}, V=$ $992.69(5) \AA^{3}$, and $Z=4, d_{\mathrm{d}} / \mathrm{g} \mathrm{cm}^{-3}=1.895$, total reflections 2258 , refined reflections (Inet $\left.>2 \sigma \mathrm{I}_{\text {net }}\right)$ ) $1908, R_{\text {int }}=0.0181$, number of parameters 145 . The structure was solved by direct methods, revealing the positions of all non-hydrogen atoms. These atoms were refined on $F^{2}$ by full matrix least-squares procedure using anisotropic displacement parameters. $R=0.0337$ ( 0.0418 , all data), $R_{\mathrm{w}}=0.1247$ ( 0.1313 , all data), GoF $=1.045$. Ca-HEDP. Data were collected on a Rigaku diffractometer at $125(2) \mathrm{K}$ with Mo-K $\alpha(\lambda=0.71073 \AA)$. Rectangular colorless plates $(0.12 \times 0.12 \times 0.03 \mathrm{~mm})$, chemical formula $\mathrm{C}_{2} \mathrm{H}_{10} \mathrm{CaO}_{9} \mathrm{P}_{2}$, $\mathrm{FW}=280.12$, triclinic, space group $P \overline{1}$, with $a=6.943(5) \AA, b=7.581(6)$ $\AA, c=9.662(6) \AA, \alpha=92.734(5)^{\circ}, \beta=106.176(10)^{\circ}, \gamma=112.524(14)^{\circ}, V=$ 444.3(5) $\AA^{3}$, and $Z=4, d_{\mathrm{c}} / \mathrm{g} \mathrm{cm}^{-3}=2.094$, total reflections 1550 , refined reflections $\left(\right.$ Inet $\left.\left.>2 \sigma \mathrm{I}_{\text {net }}\right)\right) 1415, R_{\text {int }}=0.0616$, number of parameters 129. The structure was solved by direct methods, revealing the positions of all non-hydrogen atoms. These atoms were refined on $F^{2}$ by full matrix least-squares procedure using anisotropic displacement parameters. The $\mathrm{H}$ atoms of the two crystallographically independent water molecules could not be located in the Fourier maps. $R=0.0707(0.0833$, all data), $R_{\mathrm{w}}=0.2432(0.285$, all data $), \mathrm{GoF}=1.287$. Ca-AMP. Data were collected using synchrotron radiation at $293(2) \mathrm{K}$ and $\lambda=$ $0.68890 \AA$. Prism colorless crystal $(0.2 \times 0.2 \times 0.2 \mathrm{~mm})$, chemical formula $\mathrm{C}_{3} \mathrm{H}_{19} \mathrm{CaNO}_{13.5} \mathrm{P}_{3}, \mathrm{FW}=417.97$, monoclinic, space group $P 2_{1} /$ $n$, with $a=11.236(5) \AA, b=8.459(3) \AA, c=15.532(6) \AA, \beta=90.586(1)^{\circ}$, $V=1476.1(10) \AA^{3}$, and $Z=4, d_{\mathrm{c}} / \mathrm{g} \mathrm{cm}^{-3}=1.868$, total reflections 5162 , refined reflections (Inet $\left.>2 \sigma \mathrm{I}_{\text {net }}\right)$ ) $4090, R_{\text {int }}=0.0605$, number of parameters 229 . The structure was solved by direct methods, revealing the positions of all non-hydrogen atoms. These atoms were refined on $F^{2}$ by full matrix least-squares procedure using anisotropic displacement parameters. Hydrogen atoms of water molecules could not be detected in Fourier maps. $R=0.0557\left(0.0739\right.$, all data) $R_{\mathrm{w}}=0.1354(0.1585$, all data), $\mathrm{GoF}=1.101$. Mg-PMIDA. Data were collected on a Bruker X8 Proteum diffractometer at 296(2) $\mathrm{K}$ with $\mathrm{Cu}-\mathrm{K} \alpha(\lambda=1.54178 \AA ̊$ ) $)$. Block colorless crystals $(0.12 \times 0.08 \times 0.06 \mathrm{~mm})$, chemical formula $\mathrm{C}_{10} \mathrm{H}_{30} \mathrm{MgN}_{2} \mathrm{O}_{20} \mathrm{P}_{2}, \mathrm{FW}=584.61$, monoclinic, space group $P 2_{1} / c$, with $a=7.098(2) \AA, b=26.678(8) \AA, c=12.591(3) \AA, \beta=91.191(15)^{\circ}, V=$ 2383.9(12) $\AA^{3}$, and $Z=4, d_{\mathrm{c}} / \mathrm{g} \mathrm{cm}^{-3}=1.629$, total reflections 3595 , refined reflections (Inet $>2 \sigma \mathrm{I}_{\text {net }}$ ) $1859, R_{\text {int }}=0.2516$, number of parameters 327 . The structure was solved by direct methods, revealing the positions of all non-hydrogen atoms. These atoms were refined on $F^{2}$ by full matrix least-squares procedure using anisotropic displacement parameters. Due to the fact of the poor crystallinity of the single crystal used for the analysis, the $R$ factors reported in this work are high and the completeness and bond precision are relatively low. Hydrogen atoms of water molecules could not be detected in Fourier maps. $R=0.0814$ (0.1624, all data), $R_{\mathrm{w}}=0.1711(0.2160$, all data), $\mathrm{GoF}=1.039$.

1 A. Clearfield and K. D. Demadis, Metal phosphonate chemistry: From synthesis to applications. RSC Publishing, London: 2012.

2 (a) J. Hulliger, Angew. Chem., Int. Ed. Engl., 1994, 33, 143-162; (b) P. Van der Sluis, A. M. F. Hezemans and J. Kroon, J. Appl. Crystallogr., 1989, 22, 340-344.

3 (a) D. M. Poojary and A. Clearfield, J. Organomet. Chem., 1996, 512, 237-242; (b) M. T. Wharmby, J. P. S. Mowat, S. P. Thompson and P. A. Wright, J. Am. Chem. Soc., 2011, 133, 1266-1269; (c) R. M. P. Colodrero, A. Cabeza, P. Olivera-Pastor, A. Infantes-Molina, E. Barouda, K. D. Demadis and M. A. G. Aranda, Chem.-Eur. J., 2009, 15, 6612-6618; (d) R. M. P. Colodrero, P. Olivera-Pastor, E. R. Losilla, M. A. G. Aranda, M. Papadaki, A. McKinlay, R. E. Morris, K. D. Demadis and A. Cabeza, Dalton Trans., 2012, 41, 4045-4051; (e) R. M. P. Colodrero, A. Cabeza, P. Olivera-Pastor, D. Choquesillo-Lazarte, J. M. Garcia-Ruiz, A. Turner, G. Ilia, B. Maranescu, K. E. Papathanasiou, K. D. Demadis, G. B. Hix and M. A. G. Aranda, Inorg. Chem., 2011, 50, 11202-11211.

4 (a) K. D. Demadis, M. Papadaki and I. Cisarova, ACS Appl. Mater. Interfaces, 2010, 2, 1814-1816; (b) K. D. Demadis, M. Papadaki, R. G. Raptis and H. Zhao, Chem. Mater., 2008, 20, 4835-4846; (c) K. D. Demadis, M. Papadaki, R. G. Raptis and H. Zhao, J. Solid State Chem., 2008, 181, 679-683.

5 (a) S. Lodhia, A. Turner, M. Papadaki, K. D. Demadis and G. B. Hix, Cryst. Growth Des., 2009, 9, 1811-1822; (b) R. M. P. Colodrero, A. Cabeza, P. Olivera-Pastor, J. Rius, D. Choquesillo-Lazarte, J. M. García-Ruiz, M. Papadaki, K. D. Demadis and M. A. G. Aranda, Cryst. Growth Des., 2011, 11, 1713-1722.

6 (a) A. Sonnauer and N. Stock, Solid State Sci., 2009, 11, 358-363; (b) N. Stock and S. Biswas, Chem. Rev., 2012, 112, 933-969; (c) R. M. P. Colodrero, A. Cabeza, P. Olivera-Pastor, M. Papadaki, J. Rius, D. Choquesillo-Lazarte, J. M. García-Ruiz, K. D. Demadis and M. A. G. Aranda, Cryst. Growth Des., 2011, 11, 1713-1722.

7 (a) A. J. De Kerchove and M. Elimelech, Macromolecules, 2006, 39, 6558-6564; (b) L. Li, Y. Fang, R. Vreeker, I. Appelqvist and E. Mendes, Biomacromolecules, 2007, 8, 464 468; (c) C. Karakasyan, M. Legros, S. Lack, F. Brunel, P. Maingault, G. Ducouret and D. Hourdet, Biomacromolecules, 2010, 11, 2966-2975; (d) X. Li, Q. Shen, Y. Su, F. Tian, Y. Zhao and D. Wang, Cryst. Growth Des., 2009, 9, 3470-3476. 
8 (a) M. Bishop, S. G. Bott and A. R. Barron, Chem. Mater., 2003, 15, 3074-3088; (b) K. D. Demadis and S. D. Katarachia, Phosphorus, Sulfur Silicon Relat. Elem., 2004, 179, 627-648; (c) K. D. Demadis, S. D. Katarachia, R. G. Raptis, H. Zhao and P. Baran, Cryst. Growth Des. 2006, 6, 836-838.

9 (a) S. Kunnas-Hiltunen, M. Laurila, E. Haukka, J. Vepsäläinen and M. Ahlgrén, Z. Anorg. Allg. Chem., 2010, 636, 710-720; (b) M. Kontturi, E.
Laurila, R. Mattsson, S. Peräniemi, J. Vepsäläinen and M. Ahlgrén, Inorg. Chem., 2005, 44, 2400-2406; (c) J. Jokiniemi, E. Vuokila-Laine, S. Peräniemi, J. Vepsäläinen and M. Ahlgrén, CrystEngComm, 2007, 9 , 158-164; (d) J. Jokiniemi, S. Peräniemi, J. Vepsäläinen and M. Ahlgrén, CrystEngComm, 2008, 10, 1011-1017.

10 D. Choquesillo-Lazarte and J. M. García-Ruiz, J. Appl. Crystallogr., 2011, 44, 172-176. 